\title{
INDUCCIÓN Y PROLIFERACIÓN IN VITRO DE TEJIDOS CELULARES DE BATATA (Ipomoea batatas (L.) Lam.) EN MEDIO CON 2,4-D
}

\author{
IN VITRO INDUCTION AND PROLIFERATION OF SWEET \\ POTATO (Ipomoea batatas (L.) Lam.) CELL TISSUES IN 2,4-D \\ SUPPLIED MEDIUM
}

\author{
Yohn J. Guevara ${ }^{1}$, Isidro E. Suárez*, José A. Salgado \\ Recibido para publicación: Septiembre 19 de 2011 - Aceptado para publicación: Agosto 1 de 2012
}

\begin{abstract}
RESUMEN
Con miras a contribuir con el desarrollo de un protocolo para la regeneración de plantas de batata (Ipomoea batatas (L.) Lam.) vía embriogénesis somática, se evaluó la capacidad de inducción y proliferación de tejidos celulares a partir de diferentes explantes (lámina foliar, pecíolo y la lámina foliar con el pecíolo adherido) establecidos en medio semisólido Murashige y Skoog (MS) suplido con $\left(\mathrm{mg} \mathrm{L}^{-1}\right)$ tiamina $\mathrm{HCl}(1,0)$, sacarosa (30.000), myo-inositol (100), agar (7.000) y cinco concentraciones de 2,4-D (0,0;2,26; 4,52; 9,04 y 18,08 $\mu \mathrm{M})$. La proliferación del tejido se evaluó en medio semisólido MS y MS3:1N líquido utilizando un diseño completamente al azar. Se determinó que el suministro de 2,4-D en el medio fue necesario para observar inducción en explantes de batata, el mayor porcentaje de inducción de tejido se observó cuando se utilizó la lámina foliar con el pecíolo adherido como explante. La inducción de tejido se evidenció a partir de las semanas seis y siete con tejidos de coloración amarillo-crema y consistencia compacta creciendo de los explantes. Se lograron tasas significativas $(\operatorname{Pr}<=0,05)$ de proliferación en medio semisólido y en medio líquido por efecto de la adición de 2,4-D.
\end{abstract}

Palabras clave: tejido embriogénico, batata, 2,4-D, Ipomoea, embriogénesis somática.

\begin{abstract}
With the aim to develop a regeneration protocol for sweet potato (Ipomoea batatas (L.) Lam.) plants via somatic embryogenesis, several explants (leaf blade, petiole and petioled leaf blade) were cultured on MS medium supplemented with ( $\left.\mathrm{mg} \mathrm{L}^{-1}\right)$ thiamine $\mathrm{HCl}(1,0)$, sucrose (30.000), myo-inositol (100) and five 2,4D concentrations $(0,0 ; 2,26 ; 4,52 ; 9,04$ and $18,08 \mu \mathrm{M})$ to evaluate cell tissue induction. Tissue proliferation was promoted on semisolid MS and liquid MS3:1N media and treatments were distributed with a complete randomized design. The data showed that 2,4-D was necessary for tissue induction and petioled leaf blade
\end{abstract}

${ }^{1}$ Universidad de Córdoba, Departamento de Ingeniería Agronómica y Desarrollo Rural, Carrera 6 No. 76-103, Montería-Colombia, Tel: (4) 790 8023, Fax: (4) 786 0255. *Email: isidrosuarez@hotmail.com 
produced the highest level of tissue induction (90\%). Tissue growth was evident between six and seven weeks after establishment with yellowish compact structures arising from the explants. Analysis performed showed significant effects $(\mathrm{Pr}<0,05)$ of 2,4-D on fresh mass tissue increase in both, liquid and semisolid media.

Key words: embryogenic tissue, sweet potato, 2,4-D, Ipomoea, somatic embryogenesis.

\section{INTRODUCCIÓN}

La batata (Ipomoea batatas (L.) Lam.) es una planta originaria de la zona comprendida entre la Península de Yucatán en México y la desembocadura del Río Orinoco en Venezuela (Zhang et al. 1998). China es el mayor cultivador mundial de batata $(65 \%$ del área mundial), seguido por Cuba, Haití, Nueva Guinea, Java y Uganda. Esta especie es de gran interés para la alimentación humana, la obtención de alcohol, la elaboración de concentrados para animales y la producción de almidón y $\beta$-caroteno (Hijmans et al. 2000; Vásquez y León 2006; Dhir et al. 2008). En Colombia, no existen reportes de cultivos comerciales, aunque se conoce que las zonas de mayor producción para consumo doméstico son los Montes de María y las estribaciones de la Sierra Nevada de Santa Marta.

La propagación sexual de la batata se dificulta debido a la naturaleza hexaploide (2n:90) de la especie, su limitada producción de semillas e incompatibilidad cruzada que ocurre en algunas variedades y la inestabilidad de la descendencia híbrida, por lo que los estudios relacionados con la aplicación de técnicas de cultivo in vitro que permitan explorar la posibilidad de aplicar técnicas de mejoramiento no convencional para aumentar la productividad de su cultivo resultan de gran interés (Villegas et al. 1990; Yañez 2002).
Existen reportes de estudios de cultivo in vitro de tejidos embriogénicos en batata a partir de explantes como anteras ápices raíz y pecíolos, observándose, que la inducción de tejidos embriogénicos y el desarrollo de embriones somáticos es altamente dependiente del genotipo y del tipo de explante (Tsai y Tseng 1979; Jarret et al. 1984; Liu y Cantliffe 1984; Sonnino y Mini 1993; Lowe et al. 1994; Mazrooei et al. 1997). El presente estudio ha tenido como propósito establecer un protocolo para la inducción y multiplicación de tejidos celulares en medio suplido para promover la formación de tejidos embriogénicos, como una base para la posterior regeneración de plantas de batata de la variedad "Amarilla", genotipo del cual no se conocen reportes de cultivo in vitro.

\section{MATERIALES Y MÉTODOS}

\section{Material vegetal \\ El material vegetal utilizado fue aislado de plantas de batata variedad "Amarilla" cultivadas por varios ciclos en condiciones in vitro en medio semisólido MS (Murashige y Skoog 1962) con (en $\mathrm{mg} \mathrm{L}^{-1}$ ) tiamina $\mathrm{HCl}$ $(1,0)$, sacarosa (30.000), myo-inositol (100) y agar (Sigma-Aldrich ${ }^{\circledR}$ ) (7.000). Los tres tipos de explantes evaluados fueron la lámina foliar, el pecíolo y la lámina foliar con el pecíolo adherido.}




\section{Inducción de tejidos embriogénicos}

Con el fin de evaluar el porcentaje de inducción de tejidos celulares, los explantes fueron establecidos en medio semisólido MS suplido con (en $\mathrm{mg} \mathrm{L}^{-1}$ ) tiamina $\mathrm{HCl}(1,0)$, sacarosa (30.000), myo-inositol (100), agar (7.000), y adicionado independientemente con cinco cantidades $(0,0 ; 2,26 ; 4,52 ; 9,04$ y 18,08 $\mu \mathrm{M})$ de ácido 2,4-diclorofenoxiacético (2,4-D). Los cultivos se establecieron en cajas de Petri ${ }^{\circledR}$ desechables $(94 \times 16$ mm), las cuales fueron selladas con Parafilm ${ }^{\circledR}$ y mantenidas en oscuridad durante ocho semanas a una temperatura de $25{ }^{\circ} \mathrm{C}$. Los tratamientos se distribuyeron con un diseño completamente al azar con 10 réplicas por cada tratamiento. El número de cultivos inducidos fue registrado semanalmente y el porcentaje de inducción de explantes por tratamiento calculado; en la misma frecuencia de tiempo se realizaron observaciones de las características morfológicas de los tejidos inducidos (coloración y consistencia).

\section{Proliferación de cultivos celulares}

Porciones de tejidos inducidos (200 mg aproximadamente) fueron transferidos en medio de cultivo semisólido con una formulación similar a la fase de inducción y suplido independientemente con diferentes cantidades $(0,0 ; 2,26 ; 4,52 ; 9,04 \mu \mathrm{M})$ de 2,4$\mathrm{D}$, con el fin de evaluar la proliferación de los tejidos. Los cultivos se almacenaron en las mismas condiciones indicadas para la etapa de inducción, con 10 repeticiones por cada tratamiento y registrando el incremento en el valor de masa fresca a los 3, 6, 9, 12, 15, 18, 21, 24, 27 y 30 días después de la inoculación en el medio. Alternativamente, $1 \mathrm{ml}$ de los tejidos inducidos, y decantados en medio líquido, fueron inoculados en elenmeyers de 125 cc de capacidad conteniendo $25 \mathrm{ml}$ de medio líquido MS3:1N (Witjaksono y Litz 1999); el cual consistió de sales MS modificado (149.919,41 $\mu \mathrm{M}$ de $\mathrm{NH}_{4} \mathrm{NO}_{3}$ y 299.724,04 $\mu \mathrm{M}$ de $\mathrm{KNO}_{3}$ ) con (en mg L-1) tiamina $\mathrm{HCl}(1,0)$, sacarosa (30.000), myo-inositol (100) y suplido independientemente con 0,0; 2,26; 4,52; 9,04 $\mu \mathrm{M}$ de 2,4-D. Los erlenmeyers fueron cubiertos con papel aluminio, sellados con Parafilm ${ }^{\circledR}$ y colocados en un agitador orbital (KS 501 digital IKA ${ }^{\circledR}$ ) a 120 rpm en condiciones de semioscuridad a $25{ }^{\circ} \mathrm{C}$ durante cuatro semanas. Para cada tratamiento se emplearon siete repeticiones y la medición de volumen se realizó en tubos de ensayo de 55 ml (25 x 150 $\mathrm{mm}$ ) dejando decantar el tejido y registrando el incremento del volumen de tejido.

EL pH de todos los medios se ajustó a 5,7-5,8 previo a la adición del agar, los medios fueron esterilizados en un autoclave a $120^{\circ} \mathrm{C}$ y 1,2 PSI. Los tratamientos de ambos experimentos se distribuyeron con un diseño completamente al azar y los datos se analizaron con un ANOVA con base en el modelo $Y_{i}: \mu+\alpha_{i}+$ $\epsilon_{i}$; donde $Y_{i}$ representa el incremento de masa fresca ó volumen de células precipitadas, $\mu$ es la media general, $\alpha_{i}$ representa el efecto de las concentraciones del regulador 2,4-D y $\epsilon_{i}$ representa el componente de error al azar. Cuando existieron diferencias significativas se realizó una comparación de rangos múltiples con el test de Duncan ( $p \leq 0,05)$, mientras que el contraste de Kruskall-Wallis se aplicó como alternativa no paramétrica de ANOVA. 


\section{RESULTADOS Y DISCUSIÓN}

\section{Inducción de tejidos celulares}

Los explantes cultivados en ausencia de 2,4-D permanecieron verdes y sin cambios morfológicos evidentes, mientras que aquellos cultivados en presencia de 2,4-D se tornaron de color amarillo y apariencia clorótica después de la segunda semana de establecidos en el medio, seguidamente mostraron un arrugamiento de la lámina foliar, o engrosamiento del pecíolo (Figura 1).

El suministro de auxinas en el medio ocasionó cambios en el funcionamiento y la morfología de los explantes. Algunos de los cambios celulares internos asociados al efecto de las auxinas son rompimiento de la polaridad celular, reorganización del ADN, silenciamiento o activación de genes específicos, desdiferenciación y crecimiento celular, los cuales normalmente se reflejan en forma de cambios en el color, la textura del tejido y formación de nuevos tejidos (Feher et al. 2003; González et al. 2005). En el presente estudio, la formación de tejidos celulares de coloración amarillo-crema y consistencia compacta en la superficie adaxial de los explantes se observó luego de seis semanas de cultivo, posiblemente influenciadas por los cortes en la lámina foliar, donde se concentró la mayor formación de estructuras inducidas (Figura 1). Estudios anteriores por Liu y Cantliffe (1984) y Jarret (1993) reportan inducción de tejidos en superficies abaxiales y sanas (sin heridas) de explantes foliares y ápices de batatas en medios MS suplidos con cantidades de 2,26 a 9,04 $\mu \mathrm{M}$ de 2,4-D, respuesta que posteriormente fue asociada con un efecto genotípico y de posición del explante en el medio.

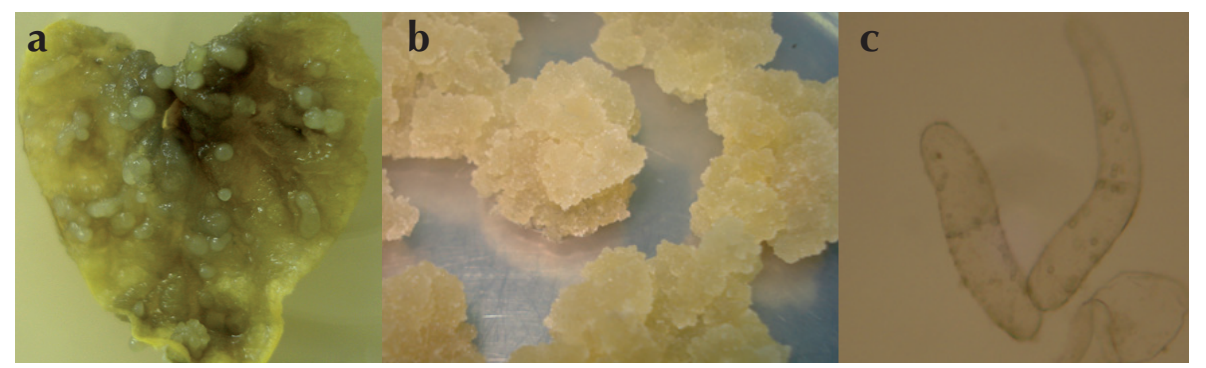

Figura 1. Tejido embriogénico de batata a los 40 días de edad: a) Inducción en tejidos foliares, b) Proliferación en medio semisólido, c) Tejidos en medio líquido.

La inducción de tejidos celulares ocurrió en todos los tratamientos suplidos con 2,4$\mathrm{D}$, mientras que en aquellos sin suministro del regulador de crecimiento no indujeron ninguna formación, lo cual indica que, bajo las condiciones en que se realizó el presente estudio, la presencia de 2,4-D en el medio fue necesaria y suficiente para inducir tejidos celulares en los explantes foliares de batata. Los mayores porcentajes de inducción (>80\%), con respecto al suministro de 2,4-D, se observó para todos los explantes cuando fueron cultivados en presencia de 2,26 $\mu \mathrm{M}$ de 2,4-D, mientras que con respecto al tipo de explante, la lámina foliar con el pecíolo adherido fue el que registró los mayores porcentajes de inducción de tejidos en las diferentes cantidades del regulador de crecimiento, exceptuando cuando se adicionó la mayor cantidad de 2,4-D (9,04 $\mu \mathrm{M})$ (Figura 2). 

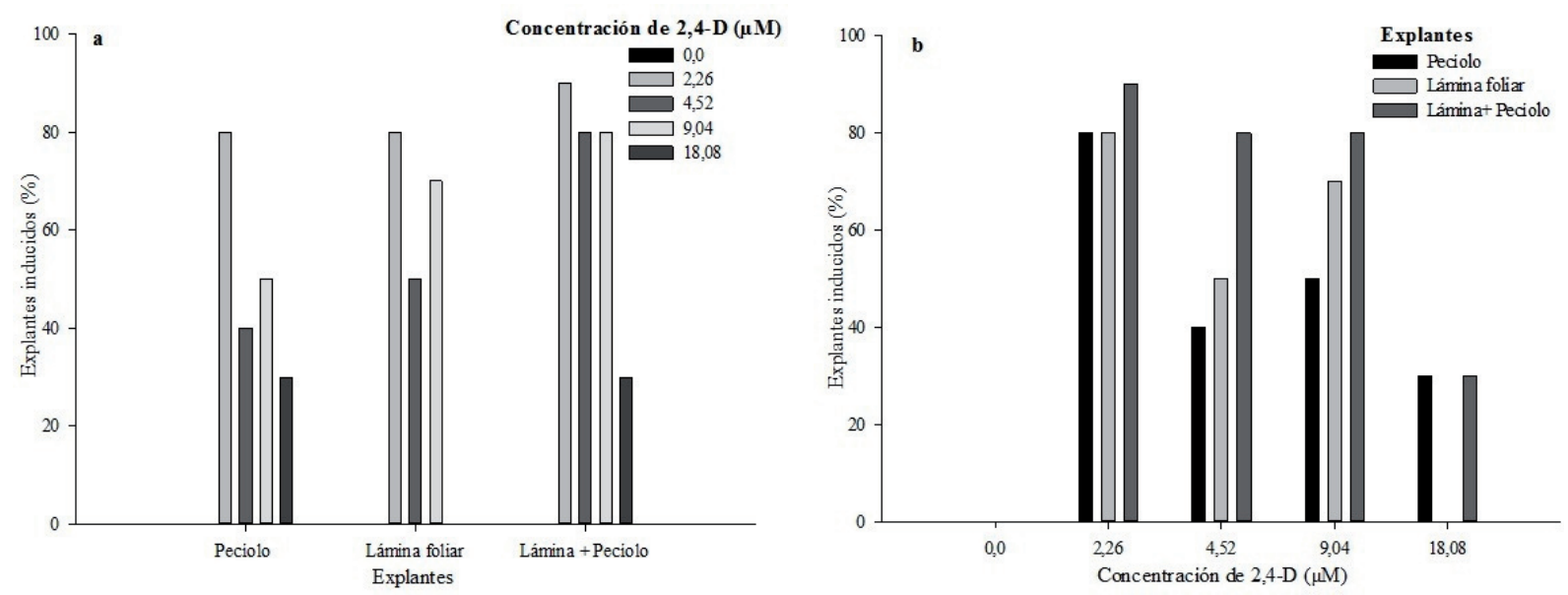

Figura 2. Porcentajes de inducción de tejidos embriogénicos: a) diferentes explantes evaluados y b) concentraciones del regulador de crecimiento vegetal 2,4-D.

Los resultados del presente estudio coinciden con reportes previos de Cantliffe (1993) y González et al. (2003), quienes observaron que los mayores porcentajes de inducción de tejidos embriogénicos ocurrieron cuando los explantes foliares (lámina foliar y lámina con el pecíolo adherido) fueron cultivados en medio con cantidades relativamente bajas de 2,4-D, lo cual indica que los tejidos inducidos en el presente estudio pueden corresponder a estructuras embriogénicas. La mayor inducción de tejidos en explantes con lámina foliar, puede ser el resultado de una mayor área de contacto de esta estructura con el medio y sus suplementos, mientras que las variaciones con respecto a la cantidad de 2,4-D suplida se asocia posiblemente con los contenidos endógenos de auxinas presentes en el explante (Guerra et al. 1999). La naturaleza embriogénica, o no, de los tejidos inducidos en el presente trabajo se sugiere verificarla en futuros estudios.

\section{Multiplicación de cultivos celulares}

Los resultados del análisis de KruskallWallis permitieron determinar que existieron diferencias estadísticamente significativas $(P=0,016)$ entre los valores de incremento en masa fresca de los tejidos cultivados por efecto de las diferentes cantidades de 2,4$\mathrm{D}$ adicionadas en el medio semisólido. Los datos de crecimiento registrados a los 30 días indicaron que los tejidos cultivados en presencia de 2,26 $\mathrm{MM}$ de 2,4-D experimentaron el mayor valor de incremento de masa fresca $(1,7 \mathrm{~g})$, contrastando con aquellos cultivados en ausencia total de 2,4-D, o en presencia 9,04 MM de 2,4-D (<600 mg). Los cultivos con mayores niveles de proliferación mostraron una fase inicial de proliferación lenta, seguida por un aumento acelerado de masa fresca entre los 15 y 20 días después de establecidos y una estabilización del crecimiento al final del período de evaluación (Figura 3a). En la evaluación del crecimiento en medio líquido, los tejidos de todos los tratamientos aumentaron el volumen de células decantadas de manera similar hasta el final de la segunda semana de cultivo, tiempo a partir del cual se observó que aquellos cultivados en presencia, indistinta de la cantidad, de 2,4-D aumentaron su volumen de manera significativa, y sostenida, 
en comparación con aquellos cultivados en presencia del tratamiento control $(\mathrm{P}<0,05)$ hasta el final del período de evaluación (30 días) (Figura 3b).

Los tejidos cultivados en medio semisólido presentaron una consistencia friable con una coloración amarrillo-crema; mientras que, aquellos cultivados en medio líquido presentaron una coloración amarilla o blanca y estaban constituidos mayoritariamente por células alargadas (Figura 1b, 1c). Morfología similar a la observada en el presente estudio ha sido reportada previamente para cultivos embriogénicos de batata inducidos de diferentes genotipos y cultivados en presencia de 2,26 a 9,04 $\mu \mathrm{M}$ de 2,4-D (Sim y Cardosa 2005).

Aunque estudios previos de embriogénesis somática en batata han coincidido en indicar que la iniciación y multiplicación del tejido embriogénico es afectada por factores como la concentración de 2,4-D, el genotipo y el tipo de explante (Jarret 1993; Sonnino y Mini 1993; Liu et al. 1993; Mazrooei et al. 1997); los resultados del presente estudio, donde se utilizó material proveniente de un mismo genotipo pero evaluando un medio diferencial con respecto a la consistencia, indican que las condiciones del medio pueden ejercer algún efecto sobre el crecimiento de los tejidos de esta especie, por lo que se recomienda seguir explorando este aspecto.

Comparativamente, los tejidos cultivados en forma de suspensiones celulares mostraron tasas de proliferación superiores a los cultivados en medio semisólido; esto se debe muy seguramente a la agitación permanente en la que se encontraban los tejidos en medio líquido, lo cual permite entre otras cosas, mantener una distribución uniforme y un contacto similar de todos los tejidos con el medio de cultivo y romper de manera permanente los cúmulos de células formadas en estructuras más pequeñas o células individuales de manera secuencial (Suárez 2005). Otro aspecto que pudo influir en la mayor proliferación de los tejidos en el medio líquido, es la diferencia en las fuentes de nitrógeno del medio MS3:1 $\mathrm{N}$, con un contenido menor de $\mathrm{NH}_{4} \mathrm{NO}_{3}$ y más alto de $\mathrm{KNO}_{3}$, lo cual
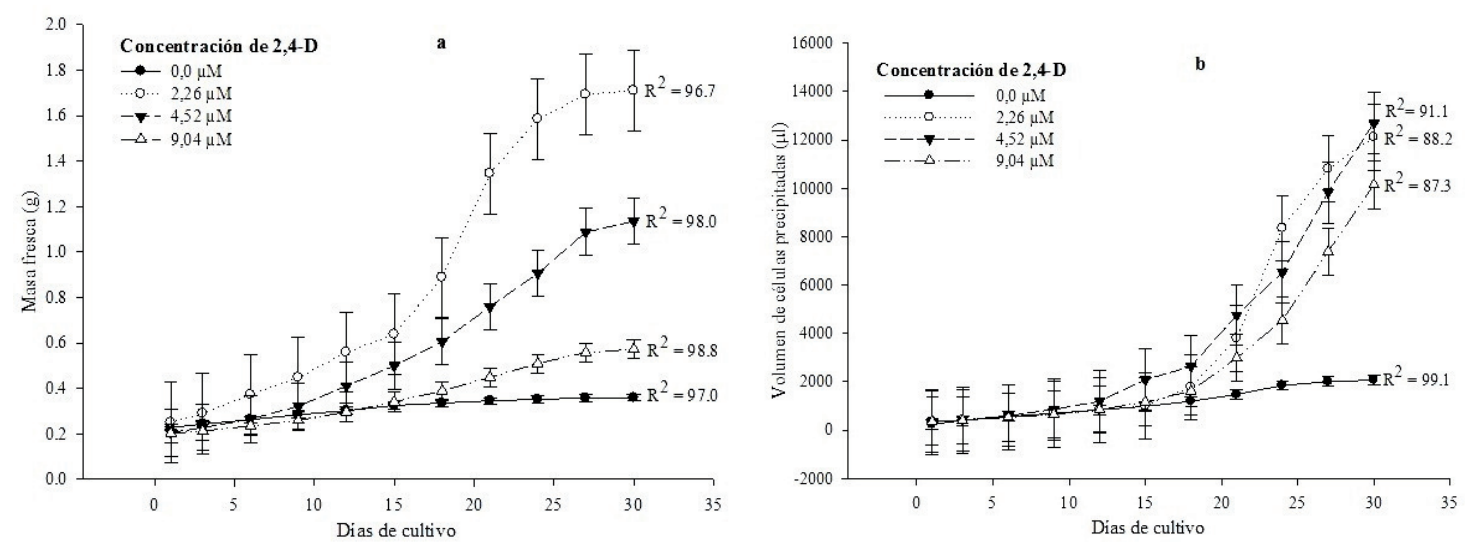

Figura 3. Curvas de crecimiento de tejido embriogénico después de cuatro semanas de cultivo, empleando diferentes concentraciones de 2,4-D: a) medio semisólido MS b) medio líquido MS3:1N, $\mathrm{R}^{2}$ representa el coeficiente de determinación (\%) de la regresión. 
ha sido comprobado favorece la viabilidad y crecimiento celular en cultivos en forma de suspensión líquida (Witjaksono y Litz 1999).

El análisis del incremento de masa fresca, tanto en medio semisólido como en medio líquido, con relación al tiempo demostró que los cultivos en ambos medios describieron una típica curva de crecimiento celular. Los tejidos cultivados en medio semisólido mostraron una fase corta de reposo durante la primera semana, seguida por un crecimiento exponencial en la segunda semana, una desaceleración progresiva del crecimiento en la tercera semana y una fase estacionaria o disminución del crecimiento al final de la cuarta semana de cultivo; mientras que para los tejidos cultivados en medio líquido, las fases de reposo inicial y la subsecuente exponencial fueron aproximadamente una semana más prolongadas. Chée y Cantliffe (1988) mencionan que los cultivos de batata en suspensión consisten de poblaciones heterogéneas de células embriogénicas, no embriogénicas y sus agregados, y de masas formadas por estos tres tipos; y que la cinética del crecimiento, la duración del ciclo celular y la fragmentación de los agregados celulares en cultivos en suspensión se ven influenciados por la concentración de 2,4-D en el medio de cultivo; recomendando que con el fin de mantener la viabilidad de las células las suspensiones embriogénicas de batata se deben transferir luego de aproximadamente 14 días de cultivo. No obstante, Liu et al. (1998) mencionan que los cultivos de batata en suspensión con 9,04 $\mu \mathrm{M}$ de 2,4-D pueden mantener su potencial embriogénico por un período de 24 semanas. En el presente estudio, cultivos con edades superiores a las cuatro semanas en medio líquido y ocho en medio semisólido mantenían la viabilidad, contario a lo que se observa en otros tipos de plantas donde el ciclo no debe superar los 30 días y los subcultivos deben realizarse antes de cumplirse la segunda semana de cultivo (Suárez et al. 2004; Suárez et al. 2006).

\section{CONCLUSIONES}

La presencia de 2,4-D en el medio de cultivo semisólido MS fue necesario, para inducir tejidos celulares con potencial embriogénico en explantes de batata e incrementar la masa fresca de tejidos cultivados, obteniendo los mayores porcentajes de cuando se establecieron explantes de la lámina foliar con el pecíolo adherido en medio suplido con 2,26 $\mu \mathrm{M}$ de 2,4-D; mientras, que el aumento del volumen del tejido en medio líquido (MS3:1N) fue independiente de las dosis utilizadas.

\section{REFERENCIAS}

Cantliffe, D. 1993. Advanced Propagation Systems for Biomass Species: A model system based on Sweet Potato. Biomass and Bioenergy. 5(1):63-69.

Chée, R. y Cantliffe, D. 1988. Selective enhancement of Ipomoea batatas Poir. Embryogenic and non-embryogenic callus growth and production of embryos in liquid culture. Plant Cell, Tissue and Organ Culture 15:149-159.

Dhir, S., Singh, H. y Dhir, S. 2008. Sweet potato. Center for Biotechnology. Department of Plant Sciences. Fort Valley State University. USA, p157. 
Feher, A., Pasternak, T. y Dudits, D. 2003.

Transition of somatic cells to an embryogenic state. Plant Cell, Tissue and Organ Culture 74:201-228.

\section{González, O., Milanés, I., Silva, J., Espinosa,}

A. y Acosta, L. 2003. Determinación de las concentraciones adecuadas de 2,4D y 6- BAP para la inducción de callos morfogénicos de boniato. Biotecnología Vegetal 3(1):25-29.

González, O., Sam, O., Hernández, M., Coronado, M. y Silva, J. 2005. Caracterización histológica de la embriogénesis somática a partir de limbos foliares de boniato (Ipomoea batatas L. Lam.). Cultivos Tropicales 26(4):37-41.

Guerra, M., Torres, A. y Teixeira, J. 1999. Embriogênese somática e sementes sintéticas. En: Torres, A., Caldas, L. y Buso, J. (editores). Culturas de Tecidos e Transformação Genética de Plantas. Brasília, Embrapa-CBAB, p533-568.

Hijmans, R., Huaccho, L. y Zhang, D. 2000. Global distribution of sweetpotato. CIP Program Report. 1999-2000. Lima. Perú, p323.

Jarret, R. 1993. Cultivo de tejidos de camote. En: Roca, W. y Mroginski, L. (editores). 1993. Cultivo de tejidos en la agricultura: Fundamentos y Aplicaciones. Centro Internacional de Agricultura Tropical. CIAT. Colombia, p421.
Jarret, R., Salazar, S. y Fernández, R. 1984. Somatic embryogenesis in sweet potato. HortScience 19:397-398.

Liu, J. y Cantliffe, D. 1984. Improved efficiency of somatic embryogenesis and plant regeneration in tissue cultures of Sweet potato (Ipomoea batatas) HortScience 19:589.

Liu, Q., Kokubu, T. y Sato, M. 1993. Varietal differences of somatic embryogenesis in shoot tip cultures of sweet potato, Ipomoea batatas (L.) Lam. Memoirs of the Faculty of Agriculture Kagoshima University 29:39-42.

Liu, Q., Zhai, H., Lu, D., Wang, Y. y Zhang, D. 1998. An efficient system of embryogenic suspension cultures and plant regeneration in sweet potato. CIP Program Report, p265.

Lowe, J., Hamilton, W. y Newell, C. 1994. Genetic transformation in Ipomoea batatas (L.) Lam. (Sweetpotato). En: Bajaj, Y. (editor). 1994. Biotechnology in Agriculture and Forestry. Vol. 29: Plant Protoplasts and Genetic Engineering V. Springer. Heidelberg, p308.

Mazrooei, S., Bhatti, M., Henshaw, G., Taylor, N. y Blakesley, D. 1997. Optimisation of somatic embryogenesis in fourteen cultivars of sweet potato (Ipomoea batatas (L.) Lam.). Plant Cell Reports 16:710-714.

Murashige, T. y Skoog, F. 1962. A revised medium for rapid growth and bioassays 
with tobacco tissue cultures. Physiology Plant 15(3):473-497.

Sim, S. y Cardosa, M. 2005. Genotype specific somatic embryogenesis in sweetpotato. Acta Horticulturae 692:119-124.

Sonnino, A. y Mini, P. 1993. Somatic embryogenesis in sweet potato Ipomoea batatas (L.) Lam. Acta Horticulturae 336:239-244.

Suárez, I. 2005. Introducción a la Biotecnología Agrícola. Producción Agrícola VI. Universidad de Córdoba. Colombia, p31.

Suárez, I., Litz, R. y Jaraba, J. 2004. Embriogénesis somática en tres cultivares de aguacate (Persea americana Mill.), Revista Temas Agrarios 9(2):32-41.

Suárez, I., Schnell, R., Khun, D. y Litz, R. 2006. Recovery and indexing of avocado plants (Persea americana) from embryogenic nucellar cultures of an avocado sunblotch viroid-infected tree. Plant Cell Tissue and Organ Culture 84:27-37.

Tsai, S. y Tseng, M. 1979. Embryos formation and plantlet regeneration from anther callus of sweet potato. Botanical Bulletin of Academia Sinica 20:117-122.
Vásquez, R. y León, C. 2006. Producción y uso de la batata (Ipomoea batatas L.); Estrategias de alimentación animal. Instituto Superior de agricultura. ISA. Santiago de los Caballeros. República Dominicana, p54.

Villegas, L., Santana, M. y Cherubini, V. 1990. Uso de plantas producidas in vitro para la producción de cultivos. Mejoramiento de cultivos a partir de material in vitro. Corporación Andina de Fomento (CAF). Programa Andino de Biotecnología de la CAF. Cap. 1:25-45.

Witjaksono. y Litz, R. 1999. Induction and growth characteristics of embryogenic avocado cultures. Plant Cell, Tissue and Organ Culture 58:19-29.

Yañez, V. 2002. Aislamiento y Caracterización de Marcadores Moleculares Microsatélites a partir de la Construcción de Librerías Genómicas Enriquecidas de Camote (Ipomoea batatas (L.) Lam.). Universidad Nacional Mayor de San Marcos. Facultad de Ciencias Biológicas. Tesis. Lima. Perú, p13.

Zhang, D., Ghislain, M., Huamán, Z. y Carey, J. 1998. AFLP assessment of sweetpotato genetic diversity in four tropical American regions. CIP Program Report 1997-1998. Lima. Perú, p303. 